Why are places so special? Uncovering how our brain reacts to meaningful places.

\title{
Why are places so special? Uncovering how our brain reacts to meaningful places.
}

\author{
Birgitta Gatersleben $^{1 *}$, Bertram Opitz ${ }^{1,3}$, Andy Myers ${ }^{2}$, Kayleigh J. Wyles ${ }^{1}$, \\ ${ }^{1}$ School of Psychology, University of Surrey, Guildford, UK \\ ${ }^{2}$ Walnut, Unlimited, London, UK \\ ${ }^{3}$ Combined Universities Brain Imaging Centre (CUBIC), Egham, UK
}

\begin{abstract}
* Corresponding author.
Address: $\quad$ School of Psychology, University of Surrey, Guildford, Surrey, GU2 7XH, UK

Email: $\quad$ b.gatersleben@surrey.ac.uk
\end{abstract}

\section{Keywords:}

Place attachment, environment, meaningful possessions, spatial processing, fMRI.

\section{Acknowledgements}

We thank Lewis Dunne for invaluable help with the data acquisition and analysis. This work was funded by the National Trust and awarded to Bertram Opitz (University of Surrey) and Andy Meyers (Walnut).

\footnotetext{
Abstract

People are drawn toward personally meaningful places. Seeing or remembering those places improves mood and supports wellbeing. But existing evidence relies on self-reports and comparisons with unpleasant places. Using brain imaging techniques, we examined reactions towards images of personally meaningful places, meaningful objects, neutral places and objects, and pre-validated (IAPS) images, among 19 volunteers (10 female) between 19 and 53 years old. A whole brain analysis showed that meaningful places and IAPS images elicited the largest response in the amygdala, associated with the processing of emotion. Similarly high activity was found for the medial prefrontal cortex (mPFC),
} 
Why are places so special? Uncovering how our brain reacts to meaningful places.

associated with self-referential processing, emotional appraisal, and memory processing. This was not found for meaningful objects or neutral places. The parahippocampal place area (PPA) showed enhanced activity only to personally meaningful places. Personally meaningful places clearly evoke distinctive neurological responses supporting the importance of this holistic and complex concept for human wellbeing. 
Why are places so special? Uncovering how our brain reacts to meaningful places.

Some places have significant meaning to people. Visiting, remembering or imagining such places can help improve mood, support recovery from stress and mental fatigue, and support emotional and cognitive self-regulation (Korpela, Hartig, Kaiser, \& Fuhrer, 2001; Korpela \& Ylén, 2009; Scannell \& Gifford, 2017b). Although existing research has provided a wealth of insight into the variables associated with meaningful places, relatively little is known about the neural correlates of such places (Lengen \& Kistemann, 2012). Moreover, it is not clear to what extent responses to meaningful places are unique to a physical setting, and thus distinct from responses to meaningful objects or other positively valanced stimuli. Using brain imaging techniques, this research examines reactions towards images of personally meaningful places and personally meaningful objects and compares those responses with neutral places and objects as well as positively and negatively valenced images with no personal meaning.

How people respond to personally meaningful places is central to different areas of research in environmental psychology and human geography, such as sense of place (Jorgensen \& Stedman, 2001; Relph, 1997), place attachment (Altman \& Low, 1992), place identity (Proshansky, Fabian, \& Kaminoff, 1983), and favourite places (Korpela, 1992). Each of these complex holistic concepts comprise of a range of affective and behavioural dimensions such as behaviours and feelings in and towards those places, memories, perceptions and social connections. Place attachment, for instance, refers to the emotional bond between people and places (Altman \& Low, 1992). It is perceived to develop over time through personal experiences. Place attachment is often seen as a sub-dimension of place identity (Proshansky et al., 1983), which in turn is seen as a substructure of identity. Proshansky et al. (1983) assert that people's relationships with others as well as with objects and places are important for the development of the self.

Existing research on holistic place concepts using predominantly self-reports has shown that places play an important role in human wellbeing. Cultural attachment theory suggests that cultural symbols such as places can function as important attachment figures to individuals; providing a sense of security and support similar to that provided by prototypical (maternal) attachment figures (Keefer, Landau, \& Sullivan, 2014; Yap, Christopoulos, \& Hong, 2017). Positive wellbeing has been associated 
Why are places so special? Uncovering how our brain reacts to meaningful places.

with places people feel attached to or identify with (Scannell \& Gifford, 2017a, 2017b). Visiting or imagining favourite places improves mood and self-esteem (Korpela \& Ylen, 2007; Korpela \& Ylén, 2009) and can support stress recovery as well as emotional and cognitive self-regulation (Korpela, Ylén, Tyrväinen, and Silvennoinen, 2008; Ratcliffe \& Korpela, 2018). On the other hand, a disruption or loss of personally meaningful places can have significant negative impacts on wellbeing (Brown \& Perkins, 1992; Fullilove, 1996; Knez et al., 2018; Lohm \& Davis, 2015). People also behave differently in and towards places that are meaningful to them. They are drawn towards them (Korpela, 2003; Korpela et al., 2001) and threats to those places evokes protective behaviour and resistance to change (Devine-Wright, 2009; Gosling \& Williams, 2010; Walker \& Ryan, 2008).

It is evident that the meaningful places are important for individual wellbeing. However, research that focuses on such holistic concepts often relies on self-reports which have several limitations, such as socially desirable responding. To overcome such limitations physiological parameters of emotional responses have been widely employed as they provide direct and automatic measures of these responses independently of any overt behaviour (Ciuk, Troy, \& Jones, 2015). A recent review of neuroscientific evidence (Lengen \& Kistemann, 2012) highlighted some key dimensions underlying people's approach to places including perception (sensory information), attention (fascination, interest), memory (personal memories), and emotion (attachment, emotional bond). Whilst the reviewed studies did indicate which brain areas are active when coding environmental information, remembering locations, and navigating spaces independently from one another, none explicitly looked at brain activity in response to holistic concepts such as sense of place, place identity, or personally meaningful places (Lengen \& Kistemann, 2012). There has been some more recent work comparing the restorative value of urban and natural environments (Tang et al., 2017), which reported increased activity in the visual and attentional focus areas in the brain when a built environment is viewed as opposed to a natural environment. This work indicates that urban landscapes require more visual attention. However, meaningful places are not exclusively natural (Kyttä, Broberg, Tzoulas, \& Snabb, 2013). The study therefore does not shed light on 
Why are places so special? Uncovering how our brain reacts to meaningful places.

the question of how holistic concepts such as personally meaningful places are represented in the brain. Autobiographical memory research has examined neurological responses to events and places belonging to people's own past (Denkova \& Manning, 2014). Distinct neurological patterns have been found when scanned respondents view images of places they have visited themselves in comparison to images of places visited by others (Rissman, Chow, Reggente \& Wagner, 2016). For instance, Cabeza et al. (2004) showed scanned participants images of a university campus either taken by the participant themselves (autobiographical condition) or by another participant (control). The autobiographical condition elicited greater activity in regions associated with self-referential processing (medial prefrontal cortex), visual/spatial memory (visual and parahippocampal regions), and recollection (hippocampus). These studies demonstrate the importance of personal experience, but they do not focus specifically on meaning; not all experiences are meaningful. Moreover, these studies do not distinguish places from objects.

In this paper we present the first study that uses neuroimaging techniques to examine reactions towards images of personally meaningful places in comparison to meaningful objects and neutral places. In order to generate informative results selecting suitable comparison stimuli is essential (Roberts \& Christopoulos, 2018). In this study we explicitly compared involuntary and controlled neural responses to meaningful places with responses to personally meaningful objects, neutral places and objects, and positive and negatively valenced images with no personal meaning to control for self-relevance of the stimuli and affective connotation.

Comparing meaningful places with meaningful objects is particularly interesting as research focusing on personally meaningful possessions has developed along many similar lines, yet almost completely independently from research on meaningful places. Literature on meaningful possessions suggests that people can form strong attachment to possessions and they can be important in managing social identities (Dittmar, 1989; Kleine, Kleine, \& Ewing, 2017). A loss of possessions negatively affects wellbeing (Ikeuchi \& Fujihara, 2000). On the other hand, attachment to possessions is also often seen as problematic for wellbeing and is associated with materialistic values (Dittmar, Bond, Hurst, \& Kasser, 
Why are places so special? Uncovering how our brain reacts to meaningful places.

2014), compulsive buying, and hoarding (Kings, Moulding, \& Knight, 2017). Comparisons between the neural responses to meaningful places and possessions will enable us to further examine whether the automaticity and intensity of evaluative emotional responses differ between the two.

Comparing responses to meaningful places and neutral places will help us to distinguish the effect of meaning from valence. Previous studies on emotional responses to environments has found overwhelming support for the potential restorative benefits of natural versus built environments (Bowler, Buyung-Ali, Knight, \& Pullin, 2010). However, this work often contrasts experiences in pleasant, calming natural environments with experiences of relatively stressful, built environments, often without controlling for meaning or memory. In contrast, our approach of comparing personally relevant with other pleasant stimuli such as pleasant but non-meaningful places or meaningful objects provides a more valid comparisons to assess emotional responses to environments associated with meaning and valance.

To summarise, in this paper we used functional Magnetic Resonance Imaging (fMRI) to examine the automatic and evaluative neural responses to meaningful places and objects in comparison with neutral places and objects and validated positively and negatively valanced images. We anticipated respondents would be more likely to positively evaluate meaningful places than neutral places.

Furthermore, neural responses to personally meaningful places are likely to include activation of areas in the brain associated with processing spatial information (the parahippocampal place area), as well as areas associated with automatic (i.e., the amygdala) and controlled (medio-frontal cortex) emotional responses. We have no specific hypotheses in relation to differences between places and objects.

\section{Method}

\section{Participants}

Twenty volunteers (11 female) were recruited from the general public in the Greater London Area via advertisements in various social media to participate in this study and were pre-screened for eligibility All participants had no metallic implants and no known history of head trauma or neurological/general medical conditions. They had normal or corrected-to-normal vision either using contact lenses or 
Why are places so special? Uncovering how our brain reacts to meaningful places.

Magnetic Resonance Imaging (MRI) compatible goggles. One participant was excluded from all analyses because of excessive motion during scanning. The remaining 19 participants (10 female) were between 19 and 53 years old (mean age $=39 ; \mathrm{SEM}=2.59$ ). The Ethics Committee of the University of Surrey reviewed and approved all procedures of the present study. Participants gave written informed consent prior to the experiment and were remunerated for their time at $£ 60$.

\section{Stimuli}

Stimuli were 60 images $(640$ x 480 px) divided into six categories. The images comprised 20 pictures of rural and urban landscapes, 20 pictures of man-made objects, and 20 images of positive and negative valence. Ten images of landscapes and ten images of objects were provided by each participants. Participants were instructed to provide images of places and objects meaningful to them. They also provided a brief description (one or two sentences) of the personal relevance of the places and objects. Five participants provided more than the required number of images. From these ten images of places and ten images of objects were selected based on image quality, meaningfulness based on the description, appropriateness as object or place and uniqueness of the object or place depicted. All respondents provided images of their holidays often showing a mix of images from cities, beaches (or similar), and places of entertainment (amusement parks, bars, pools, etc). Most images showed signs of human presence, but a minority showed identifiable people (mostly respondents themselves and/or friends and family). About a quarter provided an image of a sports environment (e.g., football stadium). Around half of the respondents provided an image reflecting home (mostly from the outside). The meaningful objects comprised a wide range of objects. Around half the respondents provided one or more pictures of a car. Around half provided images of decorative objects such as jewellery, make-up, pretty clothes or home objects such as candles, sculptures etc. Similarly, about half provided images of objects that had special social memories such as photographs of meaningful people, pictures or cards made by loved ones or wedding rings. Just under half provided images of food related objects including images of food, cookers and fridges. Just under half of the respondents provided pictures showing objects related to personal 
Why are places so special? Uncovering how our brain reacts to meaningful places.

hobbies and achievements such as instruments, sports equipment and trophies. A quarter provided a picture of a pet.

For the neutral places images were selected depicting common places like train station platform, carpark, streets, or parks but also included images depicting building interiors like a canteen. The neutral objects comprised everyday objects like lamps, hangers, chairs, or frying pan. The 20 images with positive and negative valence were selected from the International Affective Picture System (IAPS, Lang, Bradley, \& Cuthberth, 2008) database. The positive and negative images were selected to be of similar arousal (positive $M=4.76$; negative $M=4.75)$ and equal distance to neutral $(M=5.00)$ valence (positive $M=7.06$; negative $M=3.01$ ). There were additional ten images of landscapes taken by a professional photographer. These are not included in the current analyses because their different quality and the varied content of the images did not provide a meaningful comparison condition in the current study.

\section{Procedure}

During scanning participants performed a variant of the Approach-Avoidance Task (AAT) requiring them to react to a single image displayed centrally for four seconds on a computer screen by pressing one of two buttons of an MR-compatible response box with the right or left index finger to indicate approach or avoidance of that image (See Figure 1). Images were presented using E-Prime Professional 2.0 (Psychology Software Tools, Inc.) onto a translucent screen in the back of the magnet bore. Participants saw the images through a mirror attached to the head coil during fMRI acquisition for four seconds. An exponentially distributed inter-trial interval (ITI) of three to nine seconds (mean ITI = 5s) which varied in one second steps was used in order to get an optimal trade-off between detectability and estimation efficiency of the Blood Oxygenation Level Dependent (BOLD) response (Hagberg et al., 2001; Birn et al., 2002). After each image had been presented for the first time then all images were repeated twice in random order. 
Why are places so special? Uncovering how our brain reacts to meaningful places.

- Figure 1 -

\section{Imaging Parameters}

Structural and functional data were acquired with a 3T Siemens TIM Trio MR scanner with a 32channel array head coil. A T1-weighted 3D anatomical whole brain scan was performed for anatomical co-registration $\left(\right.$ MPRAGE; Siemens; TR=1830 ms, TE $=5.56 \mathrm{~ms}$, flip angle $=11^{\circ}$, resolution $=1 \times 1 \times 1$ $\mathrm{mm})$.

During functional imaging, 36 axial slices were acquired with a T2* weighted BOLD-sensitive gradient echo planar sequence $\left(\mathrm{TR}=2500 \mathrm{~ms}, \mathrm{TE}=31 \mathrm{~ms}\right.$, flip angle $=85^{\circ}$, voxel size $2 \mathrm{~mm}$ isotropic $)$. Parallel imaging (GRAPPA, acceleration factor 2) was used. In total of 756 functional volumes were acquired for each participant during the performance of the AAT.

\section{Analysis}

For the analysis of task performance proportion approach response was extracted for all images types and subjected to a series of analysis. Task compliance was evaluated by contrasting the proportion approach responses to positive and negative images using logistic regression analysis because stimuli were repeatedly presented for each person. A second analysis compared the proportion approach responses for meaningful personal objects and places with all other objects and places.

The imaging analysis was performed with SPM12

(http://www.fil.ion.ucl.ac.uk/spm/software/spm12/). The functional time series were sinc-interpolated in time to correct for differences in slice acquisition time and motion-corrected, using a 6-parameter rigid body spatial transformation and a third order B-spline interpolation. Functional slices were then coregistered to the high-resolution whole-brain anatomical scans and subsequently spatially normalized to the standard T1 template (MNI reference brain). Finally, the normalized functional images were spatially smoothed with an isotropic 8-mm FWHM Gaussian kernel and temporally high-pass filtered to $1 / 128 \mathrm{~Hz}$. 
Why are places so special? Uncovering how our brain reacts to meaningful places.

Functional data were then analysed with least-squares estimation using a mixed effects general linear model. The event-related design matrix was created by modelling the hemodynamic response function for each stimulus type separately using a box-car function with a four second duration (corresponding to the duration of the image presentation) convolved with the canonical HRF (Friston et al., 1998).

At the first level, parameters for each image type were estimated by a least-mean-squares fit of the full model including all images types as regressors to the time series using a subject-specific fixed-effects model within the general linear model for each participant. During the estimation procedure, serial correlations were estimated with a restricted maximum likelihood (ReML) algorithm using an AR(1) plus white noise model. The 3D motion parameters estimated during motion correction were added as predictors of no interest.

In the second level analysis, the beta coefficients estimated for each participant were submitted to a weighted least squares (WLS) regression where voxel-wise whole-brain T-contrasts were computed for the comparison between positive and negative IAPS images as well as for personal object/places compared to neutral places/objects. Activity was considered significant at $\mathrm{p}<0.05$, FDR corrected for multiple comparisons. Regions of interest (ROI) were then extracted from these three activity patterns using a sphere with a $10 \mathrm{~mm}$ diameter around the peak activity. In case of overlapping activity in the three contrasts the mean of the respective peak coordinates was chosen. Mean activity in these ROIs was then compared across image type and meaningfulness.

\section{Results}

\section{Approach Responses (Conscious Reaction)}

Participants complied with the task instructions and performance in AAT was uniformly high (see Table 1). The proportion approach responses to IAPS images of positive valance was significantly higher than to negative IAPS images $\left(X^{2}(1)=586.15, \mathrm{p}<.0005\right)$. The logistic regression analysis for meaningful places and objects indicated that participants more readily approached personally meaningful places and 
Why are places so special? Uncovering how our brain reacts to meaningful places.

objects than neutral places and objects (main effect meaningfulness: $X^{2}(1)=972.8, p<.0005$ ). There was also a significant but less pronounced main effect of image type $\left(X^{2}(1)=8.78, \mathrm{p}=.003\right)$. The interaction between the two factors did not reach significance $X^{2}(1)=1.63, \mathrm{p}=.20$ ) indicating that places and objects were similarly approached (cf. Table 1).

\section{- Table 1 -}

\section{Brain Activity}

To evaluate the general pattern of brain activity underlying the processing of personally meaningful places, brain activity to meaningful and neutral places, to meaningful and neutral objects as well as positive and negative IAPS images were contrasted in a whole brain analysis (See Table 2 and Figure 2). This analysis revealed three major active regions including the bilateral parahippocampal place area, the left amygdala, and the medial prefrontal cortex in both hemispheres for meaningful to neutral places. As evident from Figure 2, these regions showed a different pattern of responses to meaningful places, meaningful objects and the positive and negative IAPS images compared to neutral places and objects. In this analysis, like in the whole brain analysis, personal objects seem not to elicit any differential response compared to neutral objects. IAPS images showed increased brain activity in the amygdala and the medial prefrontal cortex. This was confirmed by comparing brain activity to meaningful places to the brain activity elicited by personally meaningful objects or IAPS images separately for each region. In the amygdala meaningful places elicited a significantly stronger brain response compared to meaningful objects $\left(t(18)=9.19, p<.001, \eta_{p}^{2}=.338\right)$ but not relative to the IAPS images $\left(t(18)<<1, \eta_{p}^{2}=.003\right)$, indicating a similar emotional response to personally meaningful places and IAPS images. A similar pattern of results was obtained in the medial prefrontal cortex. Again meaningful places elicited a stronger response than meaningful objects $\left(t(18)=5.42, p<.01, \eta_{p}^{2}=.231\right)$ while the response to IAPS images was highly similar to the response to meaningful places $(t(18)=0.17$, $\left.p=.685, \eta_{p}^{2}=.009\right)$. Crucially, the parahippocampal place area exhibited a different pattern of responses. 
Why are places so special? Uncovering how our brain reacts to meaningful places.

Here both, personal objects $\left(t(18)=13.91, p<.001, \eta_{p}^{2}=.436\right)$ and IAPS images $(t(18)=17.98, p<.001$, $\left.\eta_{p}^{2}=.500\right)$ induced significantly less activity than personally meaningful places.

- Table 2 -

- Figure 2 -

\section{Discussion}

In line with previous research, the positive and negative IAPS images used in our study elicited a large and robust response in the amygdala. Widely accepted as playing a key role in the automatic processing of emotion (Costafreda, Brammer, David, \& Fu, 2008), the amygdala is central to the intensity of any emotional response like the alert bodily state of the famous automatic fight or flight response (LeDoux, 2000) or the uplifting feeling of happiness and pleasure (Lanteaume, et al., 2006).

Consequently, this expected response demonstrates that the amygdala is responding in our study significantly to images that have emotional content. Crucially, special places also elicited a significantly higher response in the amygdala than neutral places. This suggests that the mere image of a place that is meaningful to the observer is able to trigger an automatic, unconscious emotional response in the amygdala (Haman, et al., 2002; Liberzon, et al., 2003). In contrast, personal objects did not elicit any BOLD activity higher than neutral objects in the amygdala. Evidently, personally meaningful places evoke more intense emotional responses than personally meaningful objects. It is conceivable that this was caused by the fact that personal places are more self-relevant and meaningful and hence associated with greater, more intense, emotionality.

The second brain area showing a significantly stronger response to images of personally relevant places than neutral places was the medial prefrontal cortex (mPFC). This area has been previously shown to be more engaged during the processing of positive pictures, reflects self-referential processing and emotional appraisal (D’Argembeau et al., 2007; Kensinger \& Schacter, 2006; Wrase et al., 2003) as well as memory processing (Euston et al., 2012). This result suggests that the places with personal meaning 
Why are places so special? Uncovering how our brain reacts to meaningful places.

trigger the processing of positive experiences associated with place. In contrast to the amygdala which responds in a rather automatic fashion, the $\mathrm{mPFC}$ is involved in the evaluation of a given situation; for example whether it is a positive or negative situation, or whether it evokes feelings of similar experiences, and so on. It could, therefore, be argued that the activity in the mPFC to meaningful places reflects the conscious access to the positive memories and feelings associated with that place. Such personal memories and feelings of places are fostering place attachment and, as a consequence, increase the perceived restorative qualities of those places (Ratcliffe \& Korpela, 2018).

Images of meaningful objects did not elicit strong (positive) emotional reactions. Perhaps because selection of some of these images was associated with other aspects such as functionality. Although many of the images participants submitted had strong social emotional memories associated with them (e.g., a wedding ring, a photograph of loved ones) this was not the case for all of these images. For instance, around half of the respondents provided one or more pictures of cars. Placing value on ownership and use of a car has been associated with materialistic values (Gatersleben, 2011) which is linked to lower wellbeing and negative emotions (Dittmar et al., 2014). The lack of activity in brain areas associated with automatic and controlled processing of emotions might provide an explanation for this link. Because the materialistic value of an object is culturally defined (rather than evolutionary developed) it triggers the controlled appraisal of the materialistic value without an accompanying automatic emotional response subserved by the amygdala. It is conceivable that this incongruence of automatic and controlled emotional brain responses fosters the feeling of lower wellbeing and negative emotions.

The final brain area showing a strong response to places with meaning was the parahippocampal place area (PPA). As expected, this area showed enhanced activity only to personally meaningful places but not to personally meaningful objects. In addition, IAPS pictures did not generate an increased response in this area indicating that this is a specific response to space and not emotions. Interestingly we did not find a strong response in the PPA when participants viewed pictures of neutral places. The PPA is assumed to represent the relationship between the observer and the features that define a local space 
Why are places so special? Uncovering how our brain reacts to meaningful places.

(Epstein, Graham, \& Downing, 2003). It could be argued that personally meaningful places elicited thoughts about oneself being in this place whereas images of neutral spaces did not; perhaps it is easier and more attractive to imagine oneself in a meaningful rather than a neutral place. Moreover, as noted earlier, some of the images of meaningful places had people in them, including the participant themselves which may have further enhanced this personal place immersion (Myers \& Sowden, 2008).

\section{Limitations, Future Work, and Implications}

The current study is the first study that attempted to examine the neural processes involved in the complex holistic concept of meaningful places. In line with the historical conceptual literature, it supports that meaningful places are a unique construct, which our brains process differently to other stimuli such as meaningful objects and neutral places and objects. As well as demonstrating the valuable insight neuroscientific investigation techniques can provide, these findings also highlight potential areas of future work.

Using neuroimaging techniques, future work could adjust the photograph stimuli to further understand how we process different stimuli. In this study, comparative images were carefully selected and kept constant across the participants, which is a key strength of the research. In contrast, participants needed to personally select their meaningful places, which resulted in greater spread of stimuli, ranging from very small spaces (e.g., a room) to pictures of gardens or houses, to football stadia and open natural landscapes. Some of these images showed people (including the participants themselves) or animals. Future research may consequently want to examine different types of meaningful places or focus on examining different elements of meaningful spaces to gain a better understanding of the key defining features of such spaces.

Respondents in the study were asked to bring pictures of places and objects that were meaningful to them. In their brief descriptions many respondents mentioned the picture showing a "favourite place" a concept frequently studied in previous research (Korpela \& Ylen, 2007). However, respondents were not specifically asked to report on their favourite places. They were also not specifically asked about other 
Why are places so special? Uncovering how our brain reacts to meaningful places.

key theoretical concepts such as place identity (Proshansky et al., 1983), place attachment (Altman \& Low, 1992), or sense of place (Lengen \& Kistemann, 2012). This makes it somewhat difficult to compare the findings to existing literature which has defined these concepts in different ways. Future studies may want to tap more closely into these concepts by asking people to reflect more specifically on them.

Whilst the pictures of meaningful places were very varied across participants we only included the same ten images of neutral places depicting a range of every day spaces for all participants. In almost all of them people were not clearly visible and none of the images could be labelled as particularly beautiful. Future studies may want to select a different set of neutral places that are more closely matched to the meaningful spaces in order to better control for any influence of aspects such as scenic beauty or human presence.

Further research may want to examine the potential therapeutic benefits of exposure to meaningful places. Research in the area of therapeutic landscapes is growing but much of this focuses on green spaces such as gardens or parks (Milligan, Gatrell, \& Bingley, 2004). The potential benefits of exposure to types of meaningful spaces is clearly demonstrated here as in previous research. Future research may want to use neuroscientific research techniques to provide more insight into the benefits of exposure to meaningful places in particular for people with cognitive and neurological disorders such as dementia. There is increasing research evidence to show that exposure to natural spaces can have therapeutic effects (Hernandez, 2007) but research focusing on the potential healing benefits of exposure to meaningful places is limited.

\section{Conclusions}

This paper presents the first neuroscientific study of meaningful places. In line with Lengen and Kistemann (2012) it suggests that the human brain may have developed distinct patterns of interaction with such places. Exposure to pictures of meaningful places results into activation of brain areas associated with (positive) emotional responses and spatial information processing. Such responses were not found for meaningful objects or neutral places, indicating more intense emotional responses to places 
Why are places so special? Uncovering how our brain reacts to meaningful places.

than to objects. Meaningful places are important for human wellbeing. Such places have symbolic, spiritual, social and personal value and visiting or remembering them elicits conscious and unconscious reactions. The bonds people have with meaningful places impact support (or resistance) to urban planning and policy decisions. This paper demonstrates that neuroscientific methods can help gain advanced insight into cognitive and emotional processes associated with place concepts and open up new insights and questions for research on the importance of place for human health and wellbeing. 
Why are places so special? Uncovering how our brain reacts to meaningful places.

\section{References}

Altman, I., \& Low, S. M. (1992). Place attachment (Vol. 12). New York.

Bowler, D. E., Buyung-Ali, L. M., Knight, T. M., \& Pullin, A. S. (2010). A systematic review of evidence for the added benefits to health of exposure to natural environments. BMC Public Health, 10, 456. doi:10.1186/1471-2458-10-456

Brown, B. B., \& Perkins, D. D. (1992). Disruptions in place attachment Place attachment (pp. 279-304): Springer.

Cabeza, R., Prince, S. E., Daselaar, S. M., Greenberg, D. L., Budde, M., Dolcos, F., ... \& Rubin, D. C. (2004). Brain activity during episodic retrieval of autobiographical and laboratory events: an fMRI study using a novel photo paradigm. Journal of cognitive neuroscience, 16(9), 1583-1594.

Ciuk, D., Troy, A., \& Jones, M. (2015). Measuring emotion: Self-reports vs. physiological indicators.

Denkova, E. J., \& Manning, L. (2014). FMRI contributions to addressing autobiographical memory impairment in temporal lobe pathology. World journal of radiology, 6(4), 93-105. doi:10.4329/wjr.v6.i4.93

Devine-Wright, P. (2009). Rethinking NIMBYism: The role of place attachment and place identity in explaining place-protective action. Journal of Community \& Applied Social Psychology, 19(6), 426-441. doi:10.1002/casp.1004

Dittmar, H. (1989). Gender identity-related meanings of personal possessions. British Journal of Social Psychology, 28(2), 159-171. doi:10.1111/j.2044-8309.1989.tb00857.x

Dittmar, H., Bond, R., Hurst, M., \& Kasser, T. (2014). The relationship between materialism and personal well-being: A meta-analysis. Journal of personality and social psychology, 107(5), 879-924. doi:10.1037/a0037409

Fullilove, M. T. (1996). Psychiatric implications of displacement: Contributions from the psychology of place. The American Journal of Psychiatry, 153(12), 1516-1523. doi:10.1176/ajp.153.12.1516 
Why are places so special? Uncovering how our brain reacts to meaningful places.

Gatersleben, B. (2011). The Car as a Material Possession: Exploring the Link between Materialism and Car Ownership and Use. Auto Motives: Understanding Car Use Behaviours, 137-148.

Gosling, E., \& Williams, K. J. (2010). Connectedness to nature, place attachment and conservation behaviour: Testing connectedness theory among farmers. Journal of Environmental Psychology, 30(3), 298-304.

Hernandez, R. O. (2007). Effects of therapeutic gardens in special care units for people with dementia: Two case studies. Journal of Housing for the Elderly, 21(1-2), 117-152.

Ikeuchi, H., \& Fujihara, T. (2000). The effects of loss of material possessions and social support network on the quality of life (QOL): The great Hanshin earthquake victims. The Japanese Journal of Social Psychology, 16(2), 92-102.

Jorgensen, B. S., \& Stedman, R. C. (2001). Sense of place as an attitude: Lakeshore owners attitudes toward their properties. Journal of Environmental Psychology, 21(3), 233-248.

Keefer, L. A., Landau, M. J., \& Sullivan, D. (2014). Non-human support: Broadening the scope of attachment theory. Social and Personality Psychology Compass, 8(9), 524-535.

Kings, C. A., Moulding, R., \& Knight, T. (2017). You are what you own: Reviewing the link between possessions, emotional attachment, and the self-concept in hoarding disorder. Journal of Obsessive-Compulsive and Related Disorders, 14, 51-58. doi:10.1016/j.jocrd.2017.05.005

Kleine, R. E., III, Kleine, S. S., \& Ewing, D. R. (2017). Differences in symbolic self-completion and selfretention across role-identity cultivation stages. European Journal of Marketing, 51(11-12), 18761895. doi:10.1108/EJM-09-2016-0497

Knez, I., Butler, A., Sang, Å. O., Ångman, E., Sarlöv-Herlin, I., \& Åkerskog, A. (2018). Before and after a natural disaster: Disruption in emotion component of place-identity and wellbeing. Journal of Environmental Psychology, 55, 11-17. doi:10.1016/j.jenvp.2017.11.002

Korpela, K. M. (1992). Adolescents' favourite places and environmental self-regulation. Journal of Environmental Psychology, 12(3), 249-258. doi:10.1016/S0272-4944(05)80139-2 
Why are places so special? Uncovering how our brain reacts to meaningful places.

Korpela, K. M. (2003). Negative mood and adult place preference. Environment and Behavior, 35(3), 331-346.

Korpela, K. M., Hartig, T., Kaiser, F. G., \& Fuhrer, U. (2001). Restorative experience and self-regulation in favorite places. Environment and Behavior, 33(4), 572-589. doi:10.1177/00139160121973133

Korpela, K. M., \& Ylen, M. (2007). Perceived health is associated with visiting natural favourite places in the vicinity. Health \& Place, 13(1), 138-151. doi:10.1016/j.healthplace.2005.11.002

Korpela, K. M., Ylén, M., Tyrväinen, L., \& Silvennoinen, H. (2008). Determinants of restorative experiences in everyday favorite places. Health \& Place, 14(4), 636-652.

Korpela, K. M., \& Ylén, M. P. (2009). Effectiveness of favorite-place prescriptions: A field experiment. American Journal of Preventive Medicine, 36(5), 435-438. doi:10.1016/j.amepre.2009.01.022

Kyttä, M., Broberg, A., Tzoulas, T., \& Snabb, K. (2013). Towards contextually sensitive urban densification: Location-based softGIS knowledge revealing perceived residential environmental quality. Landscape and Urban Planning, 113, 30-46.

Lengen, C., \& Kistemann, T. (2012). Sense of place and place identity: Review of neuroscientific evidence. Health \& Place, 18(5), 1162-1171.

doi:https://doi.org/10.1016/j.healthplace.2012.01.012

Lohm, D., \& Davis, M. (2015). Between bushfire risk and love of environment: Preparedness, precariousness and survival in the narratives of urban fringe dwellers in Australia. Health, Risk \& Society, 17(5-6), 404-419. doi:10.1080/13698575.2015.1109614

Milligan, C., Gatrell, A., \& Bingley, A. (2004). 'Cultivating health': Therapeutic landscapes and older people in northern England. Soc Science \& Med, 58. doi:10.1016/s0277-9536(03)00397-6

Myers, A., \& Sowden, P. T. (2008). Your hand or mine? The extrastriate body area. NeuroImage, 42(4), 1669-1677. doi:https://doi.org/10.1016/j.neuroimage.2008.05.045

Proshansky, H. M., Fabian, A. K., \& Kaminoff, R. (1983). Place-identity: Physical world socialization of the self. Journal of Environmental Psychology, 3(1), 57-83. 
Why are places so special? Uncovering how our brain reacts to meaningful places.

Ratcliffe, E., \& Korpela, K. M. (2018). Time- and self-related memories predict restorative perceptions of favorite places via place identity. Environment and Behavior, 50(6), 690-720. doi:10.1177/0013916517712002

Relph, E. (1997). Sense of place. Ten geographic ideas that changed the world, 205-226.

Rissman, J., Chow, T. E., Reggente, N., \& Wagner, A. D. (2016). Decoding fMRI signatures of realworld autobiographical memory retrieval. Journal of cognitive neuroscience, 28(4), 604-620.

Roberts, A. C., \& Christopoulos, G. I. (2018). Comment on "Using functional Magnetic Resonance Imaging (fMRI) to analyze brain region activity when viewing landscapes”. Landscape and Urban Planning, 172, 25-28. doi:https://doi.org/10.1016/j.landurbplan.2017.12.006

Russell, J. A., \& Snodgrass, J. (1987). Emotion and the environment. Handbook of environmental psychology, 1(1), 245-281.

Scannell, L., \& Gifford, R. (2017a). The experienced psychological benefits of place attachment. Journal of Environmental Psychology, 51, 256-269. doi:10.1016/j.jenvp.2017.04.001

Scannell, L., \& Gifford, R. (2017b). Place attachment enhances psychological need satisfaction. Environment and Behavior, 49(4), 359-389. doi:10.1177/0013916516637648

Tang, I.-C., Tsai, Y.-P., Lin, Y.-J., Chen, J.-H., Hsieh, C.-H., Hung, S.-H., . . Chang, C.-Y. (2017). Using functional Magnetic Resonance Imaging (fMRI) to analyze brain region activity when viewing landscapes. Landscape and Urban Planning, 162, 137-144.

Walker, A. J., \& Ryan, R. L. (2008). Place attachment and landscape preservation in rural New England: A Maine case study. Landscape and Urban Planning, 86(2), 141-152.

Yap, W. J., Christopoulos, G. I., \& Hong, Y. Y. (2017). Physiological responses associated with cultural attachment. Behavioural brain research, 325, 214-222. 
Why are places so special? Uncovering how our brain reacts to meaningful places. 
Why are places so special? Uncovering how our brain reacts to meaningful places.

Table 1 Mean proportion approach responses for each of the six categories

\begin{tabular}{|c|c|c|}
\hline & \multicolumn{2}{|c|}{ proportion approach responses } \\
\cline { 2 - 3 } & Mean & Std. Error \\
\hline personally meaningful objects & 0.993 & 0.005 \\
\hline neutral everyday objects & 0.473 & 0.081 \\
\hline personally meaningful places & 0.977 & 0.010 \\
\hline neutral urban and rural places & 0.412 & 0.086 \\
\hline negative IAPS images & 0.055 & 0.022 \\
\hline positive IAPS images & 0.708 & 0.048 \\
\hline
\end{tabular}


Why are places so special? Uncovering how our brain reacts to meaningful places.

Table 2 Brain regions exhibiting greater brain activity in response to personally meaningful places compared to neutral places.

\begin{tabular}{|c|c|c|c|c|c|c|c|}
\hline \multirow[t]{3}{*}{ Brain region } & \multirow[t]{3}{*}{ Hemisphere } & \multirow{3}{*}{$\begin{array}{l}\text { cluster size } \\
\qquad\left[\mathrm{mm}^{3}\right]\end{array}$} & \multirow{3}{*}{$\begin{array}{c}\mathrm{T}- \\
\text { value } \\
\text { at peak }\end{array}$} & \multirow{3}{*}{$\begin{array}{l}\mathrm{p} \text {-value } \\
\text { at peak }\end{array}$} & \multicolumn{3}{|c|}{ peak coordinates } \\
\hline & & & & & $\mathrm{x}$ & $\mathrm{y}$ & $\mathrm{z}$ \\
\hline & & & & & & & \\
\hline Amygdala & left & 108 & 4.84 & 0.000 & -26 & 0 & -26 \\
\hline Parahippocampal Place Area & left & 513 & 6.43 & 0.000 & -18 & -36 & -18 \\
\hline Parahippocampal Place Area & right & 324 & 4.30 & 0.000 & 16 & -24 & -16 \\
\hline Medial Frontal Cortex & midline & 135 & 4.00 & 0.001 & 0 & 60 & 16 \\
\hline
\end{tabular}


Why are places so special? Uncovering how our brain reacts to meaningful places.

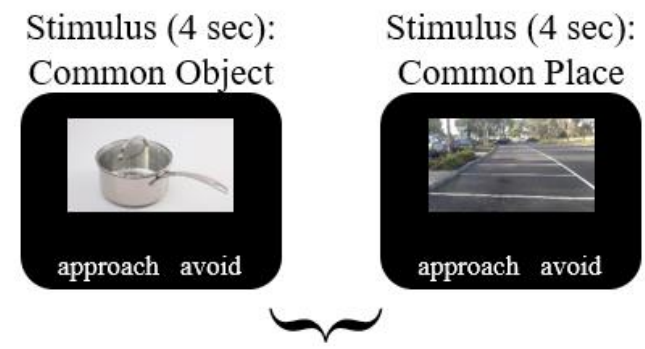

variable ITI $=5 \mathrm{sec}($ range: $3-9 \mathrm{sec})$

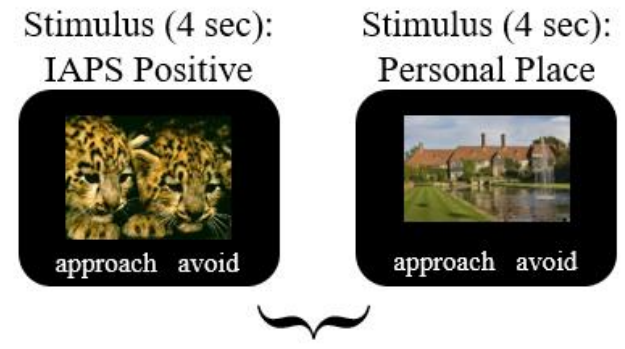

variable ITI

Figure 1. Example stimuli and task procedure. Individual stimuli were presented for $4 \mathrm{sec}$ on the screen with response options displayed underneath. The intertrial interval (ITI) was drawn from an exponential distribution in one second steps from three to nine seconds with a mean ITI of five seconds. 
Why are places so special? Uncovering how our brain reacts to meaningful places.

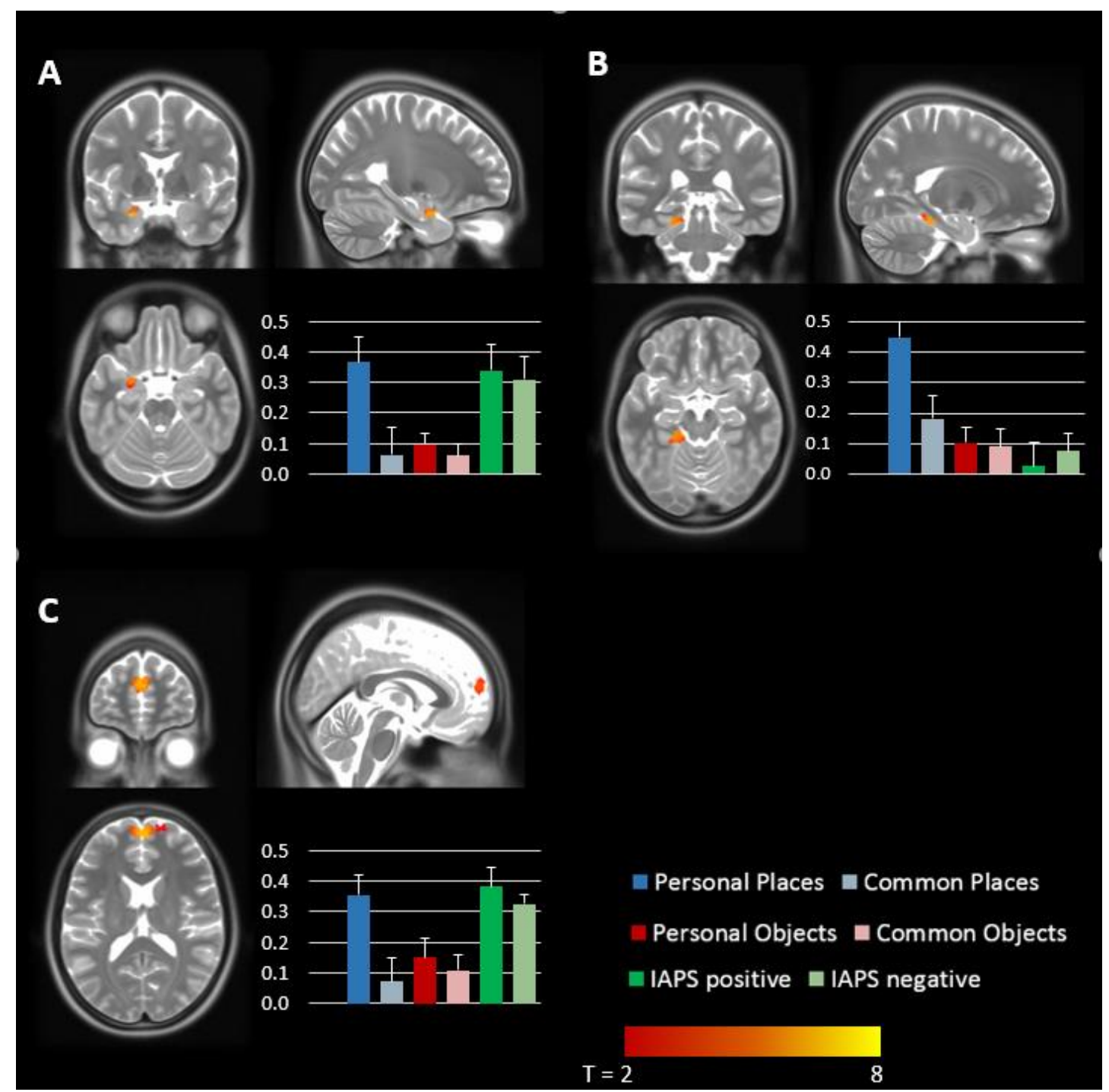

Figure 2. Brain Activity (\% Signal Change) in the Amygdala (A), the Parahippocampal Place Area (B) and the Medial Frontal Cortex (C). Bar graphs represent the percent signal change in each of the activated areas in response to each of the six image types separately. 